Volume 1, Issue 2, Serial 2: September 2012

\title{
DISSOLUTION ENHANCEMENT OF POORLY SOLUBLE DRUG BY SOLVENT EVAPORATION METHOD USING HYDROPHILIC POLYMER: A SOLID DISPERSION TECHNIQUE
}

Md. Armin Minhaz ${ }^{1}$, Md. Mofizur Rahman ${ }^{2^{*}}$, Md. Qamrul Ahsan ${ }^{1}$, Abul Bashar Ripon Khalipha ${ }^{2}$ and Mohammed Raihan Chowdhury ${ }^{1}$

1Department of Pharmacy, University of Asia pacific, Dhaka, Bangladesh

${ }^{2}$ Department of Pharmacy, Bangladesh University, Dhaka, Bangladesh

\section{Abstract}

In order to investigate the effect of polymers on release mechanism of poorly soluble drugs from solid dispersions, Clonazepam was used as a model drug for these purposes. Five types of solid dispersions were prepared using polyethylene glycol 6000 (PEG- 6000), Kollicoat IR, Kollidon VA 64 and Poloxomer in different drug-tocarrier ratios $(1: 2,1: 4,1: 6,1: 8,1: 10)$. The solvent evaporation method was used for preparation of solid dispersions. The in-vitro dissolution study with temperature of $37^{\circ} \mathrm{C}$ and a paddle method, $100 \mathrm{rpm}$ was used in $1000 \mathrm{ml}$ of distilled water as dissolution medium in each dissolution basket for the pure drug and solid dispersions. For pure Clonazepam showed very slow dissolution rate and the solid dispersion considerably enhanced the dissolution rate. Decreased crystalline and increased amorphous fraction of the drug was probably done by wettability and dispersibility. The highest improvement in wettability and dissolution rate of Clonazepam was observed in PEG-6000, Poloxomer and Kollidon VA 64 (1:10 ratio).

\footnotetext{
Corresponding author:

"Md. Mofizur Rahman

Department of Pharmacy, Bangladesh University, Dhaka-1207, Bangladesh

Tel: +8801911605139, E-mail: rmfi02@yahoo.com
} 
Volume 1, Issue 2, Serial 2: September 2012

Solid dispersions containing polymer (1:10 ratio) prepared by solvent method showed significant improvement in the release profile as compared to pure drug, Clonazepam.

Key words: Clonazepam, Solid dispersions, PEG 6000, Kollicoat IR, Kollidon VA 64

\section{Introduction}

The mechanisms for the enhancement of the dissolution rate of solid dispersions have been proposed by several investigators. Molecular dispersion of drug in polymeric carriers may lead to particle size reduction and surface area enhancement, which results improved dissolution rates. Furthermore, no energy is required to break up the crystal lattice of a drug during dissolution process and improvement of drug solubility and wettability due to surrounding hydrophilic carriers $^{1}$. Most of the recently introduced drugs suffer from poor solubility as they are developed by combinatorial chemistry and high throughput screening techniques. Solid dispersions are useful for solving the solubility and bioavailability problem of such drugs ${ }^{2}$. By definition solid dispersions are formulations of finely crystalline or amorphous drug dispersed in an inert matrix ${ }^{3}$. Reduction or absence of aggregation and agglomeration may also contribute to increased dissolution. The methods used to prepare solid dispersions include the melting method, the solvent method, and the solvent wetting method ${ }^{4,5}$. Among various approaches employed to improve the dissolution of poorly soluble drugs, solid dispersion has been proven successful. Fast or immediate drug dissolution from solid dispersions has been observed due to increased wettability, improved dispersibility of drug particles, and existence of the drug in amorphous form with improved solubility and absence of aggregation of drug 
International Journal of Pharmaceutical and Life Sciences

ISSN 2305-0330

Volume 1, Issue 2, Serial 2: September 2012

particles ${ }^{6}$. Literature shows that the solvent evaporation method has been used for the preparation of solid dispersions for dissolution enhancement ${ }^{7}$.

Polymeric carriers are the most successful for solid dispersions, because they are able to originate amorphous solid dispersions. They are divided into fully synthetic polymers and natural product-based polymers. Fully synthetic polymers include povidone (PVP), polyethyleneglycols (PEG) and polymethacrylates. Natural productbased polymers are mainly composed by cellulose derivatives, such as hydroxypropylmethylcellulose (HPMC), ethylcellulose or hydroxypropylcellulose or starch derivates, like cyclodextrins. Amorphous solid dispersions can be classified according to the molecular interaction of drug and carriers in solid solutions, solid suspensions or a mixture of both. In amorphous solid solutions, drug and carrier are totally miscible and soluble, originating a homogeneous molecular interaction between them. In these systems, the drug and carrier interaction energy is extremely high, resulting in a really true solution ${ }^{8}$.

In the present experiment Clonazepam belongs to a class of anticonvulsants that enhances gamma-aminobutyric acid (GABA) receptor responses. Anticonvulsants used for several types of seizures, including myotonic or atonic seizures, photosensitive epilepsy, and absence seizures. Clonazepam exerts its action by binding to the benzodiazepine site of the GABA receptors, which causes an enhancement of the electric effect of GABA binding on neurons resulting in an increased influx of chloride ions into the neurons. This results in an inhibition of synaptic transmission across the central nervous system ${ }^{9,}{ }^{10}$. Clonazepam is a light yellow crystalline powder which is practically odorless. It is freely very soluble in 
Volume 1, Issue 2, Serial 2: September 2012

methanol, ethanol, and acetone, and practically insoluble in water (at $25^{\circ} \mathrm{C}<$ $0.1 \mathrm{mg} / \mathrm{ml}$ ). It is generally considered that compounds with very low aqueous solubility will show dissolution rate-limited absorption and, hence, poor absorption, distribution, and target organ delivery ${ }^{11}$. Improvement of aqueous solubility in such a case is a valuable goal to improve therapeutic efficacy.

Several attempts have been reported in literature using solid dispersion technique to increase the dissolution characteristics where Hydroxy Propyl methyl cellulose (HPMC), polyvinylpyrrolidone (PVP), polyethylene glycol, sodium carboxymethyl cellulose, sodium starch glycolate, pregelatinized starch were used as solubilizing agents ${ }^{12-14}$.

In this study, solid dispersions were formulated with three water soluble polymers by solvent evaporation technique. Micronized poloxamer 407, Kollicoat IR and Kollidon VA 64 were utilized for this purpose. Poloxamers are nonionic polyoxyethylene-polyoxypropylene copolymers used primarily as emulsifiers, solubilizing agents, wetting agents and have been reported for enhancing the solubility and bioavailability of sparingly soluble drugs in solid dosage forms ${ }^{15-17}$. Solid dispersions were prepared with poloxamer by melting method for rofecoxib and ibuprofe ${ }^{18}$. Reduced crystalline structure and improved wettability ${ }^{19,20}$ were mentioned as the mechanism by which poloxamer can enhance dissolution from solid dispersions. Solid dispersions formulations of gliclazide can be successfully used to design a solid dosage form of the drug, which would have significant advantages over the current marketed tablets $^{21}$. 
International Journal of Pharmaceutical and Life Sciences

ISSN 2305-0330

Volume 1, Issue 2, Serial 2: September 2012

The objective of the present study was to improve the solubility of Clonazepam by using three different types of water soluble polymers. The formulations were characterized by in vitro dissolution study to compare the effects of polymers on the preparation of solid dispersion and dissolution enhancement.

\section{Materials and methods}

Materials: Clonazepam was a gift sample from Rangs Pharmaceuticals Ltd., Dhaka, Bangladesh. Poloxamer 407 (Lutrol 127), Kollicoat IR and Kollidon VA 64 was gifted by BASF, PEG 6000 (Loba Chemie, India), reagent grade methanol (Merck, Germany) were purchased from the market.

\section{Preparation of solid dispersions}

Solid dispersion with different polymer showed in the table 1-3. $50 \mathrm{mg}$ of clonazepam was taken in the vial and $4 \mathrm{ml}$ acetone was added in each. The drug was completely dissolved in the solvent. Then different types of polymer were added in the solution and sonicated it for $1 \mathrm{~min}$. All solutions were dried by hot air. When the solutions were evaporated completely, they were stored in a dessicator. The formulations were withdrawn from vials, crushed by morter and pestle, passed through 36 micron sieves. Finally lactose was added in the formulation. Then formulations were transferred in vials and stored in a dessicator. A slightly different approach was warranted for solid dispersions containing poloxamer as it is low melting substance (melting temp. $52-57^{\circ} \mathrm{C}$ ) and melting method was most suitable for this polymer ${ }^{18,19}$. The drug was dispersed with methanol in a glass flask and heated in a water bath at $50^{\circ} \mathrm{C}$. Poloxamer was added to the dispersion and it was melted at that temperature. The solvent was evaporated during constant mixing and the resulting solid mass was 


\section{International Journal of Pharmaceutical and Life Sciences \\ ISSN 2305-0330}

Volume 1, Issue 2, Serial 2: September 2012

dried at $40^{\circ} \mathrm{C}$ in hot air oven. The dried samples were crushed by mortar and pestle followed by sieving through 30 mesh screen. The ratio between drug and polymer for all formulations was kept at 1:2, 1:4, 1:6, 1:8 and 1:10.

Table 1. Formulation of clonazepam solid dispersion by changing the amounts of Kollicoat IR with PEG 6000

\begin{tabular}{ccccccc}
\hline \multicolumn{7}{c}{ Formulation of solid dispersion } \\
Component & $\mathrm{F} 1$ & $\mathrm{~F} 2$ & $\mathrm{~F} 3$ & $\mathrm{~F} 4$ & $\mathrm{~F} 5$ & $\mathrm{F6}$ \\
& $(\mathrm{mg})$ & $(\mathrm{mg})$ & $(\mathrm{mg})$ & $(\mathrm{mg})$ & $(\mathrm{mg})$ & $(\mathrm{mg})$ \\
\hline Clonazepam & 50 & 50 & 50 & 50 & 50 & 50 \\
PEG 6000 & 100 & 100 & 100 & 100 & 100 & 100 \\
Kollicoat IR & 500 & 400 & 300 & 200 & 100 & 0 \\
Lactose $(\mathrm{g})$ & 3 & 3 & 3 & 3 & 3 & 3 \\
\hline
\end{tabular}

Table 2. Formulation of clonazepam solid dispersion by changing amounts of Kollidon VA 64 with PEG 600

Formulation of solid dispersion

\begin{tabular}{lllllll} 
Component & F1 & F2 & F3 & F4 & F5 & F6 \\
& $(\mathrm{mg})$ & $(\mathrm{mg})$ & $(\mathrm{mg})$ & $(\mathrm{mg})$ & $(\mathrm{mg})$ & $(\mathrm{mg})$ \\
\hline Clonazepam & 50 & 50 & 50 & 50 & 50 & 50 \\
PEG 6000 & 100 & 100 & 100 & 100 & 100 & 100 \\
Kollidon VA 64 & 500 & 400 & 300 & 200 & 100 & 0 \\
Lactose (g) & 3 & 3 & 3 & 3 & 3 & 3 \\
\hline
\end{tabular}


Volume 1, Issue 2, Serial 2: September 2012

Table 3. Formulation of clonazepam solid dispersion by changing the amounts of Poloxomer 407 with PEG 6000

\section{Formulation of solid dispersion}

\begin{tabular}{lcccccc} 
Formulation & $\mathrm{F} 1$ & $\mathrm{~F} 2$ & $\mathrm{~F} 3$ & $\mathrm{~F} 4$ & $\mathrm{~F} 5$ & $\mathrm{F6}$ \\
& $(\mathrm{mg})$ & $(\mathrm{mg})$ & $(\mathrm{mg})$ & $(\mathrm{mg})$ & $(\mathrm{mg})$ & $(\mathrm{mg})$ \\
\hline Clonazepam & 50 & 50 & 50 & 50 & 50 & 50 \\
PEG 6000 & 100 & 100 & 100 & 100 & 100 & 100 \\
Poloxomer 407 & 500 & 400 & 300 & 200 & 100 & 0 \\
Lactose (g) & 3 & 3 & 3 & 3 & 3 & 3 \\
\hline
\end{tabular}

\section{Preparation of standard curve of clonazepam in distilled water}

$10 \mathrm{mg}$ of Clonazepam was accurately weighted \& dissolved in $100 \mathrm{ml}$ of Methanol to produce a solution $0.1 \mathrm{mg} / \mathrm{ml}$ for preparation of a standard curve for Clonazepam. Then $20 \mathrm{ml}$ of preparation was taken and made up to $100 \mathrm{ml}$ with distil water. Then 1 , $2,3,4,5,6,7,8,9 \& 10 \mathrm{ml}$ of this solution was taken in $10 \mathrm{ml}$ volumetric flask \& 9 , 8 , $7,6,5,4,3,2,1 \& 0 \mathrm{ml}$ distil water was added to them for the purpose of serial dilution. This serial dilution was carried out to get different Clonazepam concentration. These were then analyzed by UV spectrophotometer at $254 \mathrm{~nm}$ and absorbance was noted. Then the absorbance values were plotted against drug concentration and standard curve of Clonazepam was produced.

\section{Quantitative assay}

Formulation containing clonazepam was taken in a morter and triturated properly until fine powder was formed. $5 \mathrm{mg}$ equivalent of fine powder was taken in a $10 \mathrm{ml}$ volumetric flask with the help of a funnel. $5 \mathrm{ml}$ methanol and $5 \mathrm{ml}$ distil water was added with the powder, sonicated in a sonicator to make a clear solution and then finally was filtered. From this solution $2 \mathrm{ml}$ drug solution was withdrawn and taken in 
a $100 \mathrm{ml}$ volumetric fiask. The volume of drug solution was then adjusted up to 100 $\mathrm{ml}$ with distil water. In the same way, $10 \mathrm{mg}$ equivalent of fine powder was taken in a $25 \mathrm{ml}$ volumetric flask with the help of a funnel. $10 \mathrm{ml}$ methanol and $15 \mathrm{ml}$ distil water was added with the powder, sonicated in a sonicator to make a clear solution and then finally was filtered. From this solution $2 \mathrm{ml}$ drug solution was withdrawn and taken in a $100 \mathrm{ml}$ volumetric fiask. The volume of drug solution was then adjusted up to $100 \mathrm{ml}$ with distil water. For reagent blank $1 \mathrm{ml}$ methanol was transferred into a $100 \mathrm{ml}$ volumetric flask, diluted to $100 \mathrm{ml}$ with distil water. Absorbance value was determined using UV-spectrophotometer (UV-mini-1240, SHIMADZU CORP., Kyoto, Japan), at $254 \mathrm{~nm}$. Solutions were also diluted if necessary. Using the absorbence value, the amount of clonazepam entrapped was determined with the help of standard curve.

\section{In-vitro release study of Clonazepam from solid dispersion}

A paddle type Dissolution Apparatus (USP Type II Dissolution Apparatus, VEEGO, INDIA) used in in-vitro dissolution study. In a fixed amount of solid dispersion containing $10 \mathrm{mg}$ equivalent clonazepam from each batch was calculated for dissolution purpose. Distil water was used as dissolution media. $1000 \mathrm{ml}$ of distil water was used as dissolution medium in each dissolution basket at a temperature of $37^{\circ} \mathrm{C}$ and a paddle speed of $100 \mathrm{rpm}$. The fixed amou nt of solid dispersion from each batch was weighed and transferred in each dissolution basket. The dissolution was carried out for 1 hour and $5 \mathrm{ml}$ sample was withdrawn at predetermined intervals of $5,10,15,20,30,40,50 \& 60$ minutes. Each and every time $5 \mathrm{ml}$ dissolution sample was compensated by another fresh $5 \mathrm{ml}$ distil water. 
International Journal of Pharmaceutical and Life Sciences

ISSN 2305-0330

Volume 1, Issue 2, Serial 2: September 2012

Dissolution samples were withdrawn with the help of disposable syringe filter and were kept in a test tube. The dissolution samples were then analyzed spectrophotometrically by UV-VIS spectrophotometer (UV-mini-1240, SHIMADZU CORP., Kyoto, Japan) at $254 \mathrm{~nm}$ and absorbance was noted. The dissolution study for each batch was performed in triplicate. These were then analyzed by UV spectrophotometer

\section{Results and discussion}

The effects of three water soluble polymers (Kollicoat IR, Kollidon VA 64 and poloxamer 407) on the formulations of Clonazepam solid dispersions were compared. The potencies of Clonazepam in prepared solid dispersions were analyzed by UV spectrophotometer and the results were within $99-100 \%$ in all cases which indicates uniform mixing of the dispersions.

\section{Dissolution studies}

The enhancement of polymers on drug release from solid dispersion was evaluated by comparing the solubility of drug present in the mixtures as well as of pure drug. The in vitro dissolution testing was performed for 45 minutes to ascertain the effect of formulations on immediate drug release enhancement. Theoretically the solid dispersions improve drug dissolution by decreasing particle size, formation of amorphous forms and improve wettability ${ }^{2}$. The better dissolution rate of solid dispersion may be due to an improved wettability of drug particles, a significant reduction in particle size during formation of solid dispersion and dissolution due to increase in the surface area of drug, proper dispersion and increase in the amorphicity of drug by adsorption on the surface of adsorbent. High rate of 
dissolution of soluble polymer component of solid dispersion along with more insoluble but finely mixed drug into dissolution medium is the factor for fast dissolution of drug. Compacting poorly water-soluble drug particles with different hydrophilic polymers like HPMC, Kollicoat IR, PVP and Chitosan particles resulted in a granular powder having enhanced drug solubility and dissolution properties. Drug dissolution rates were comparably high for compacted granules then their physical mixture and drug alone, suggesting that compaction processes with hydrophilic polymers improve the drug dissolution rate. The mechanism is believed to be a microenvironment polymer effect facilitated by keeping the polymers and drug particles in close proximity during drug dissolution ${ }^{22}$.

\section{Comparison of \% release of Drug from Formulation of Kollicoat IR}

From the curve it is observed that increasing of Kollicoat IR when other polymer were fixed, the drug release was increased significantly. In the case of pure drug, release was decreased than drug with combination of other polymers. When Kollicoat IR was increased, drug release from solid dispersion was increased significantly due to wetting ability and convert crystalline to amorphous. The formulation containing increased Kollicoat IR increased drug release.

The formulation containing 1:10 drug-polymer, the drug release was highest due to wetting ability (Fig. 1). At high concentration, Kollicoat IR provides wetting of drug and improves dissolution. The increase in dissolution rate of drug in the presences of carriers could be attributed to an increasingly effective solubilization process. Because of the formation of amorphous phases, the dissolution rate is very high 
Volume 1, Issue 2, Serial 2: September 2012

since the drug simply dissolved along with the polymer. Therefore, the high aqueous solubility and low viscosity of Kollicoat IR enhances the dissolution process ${ }^{23,24}$.

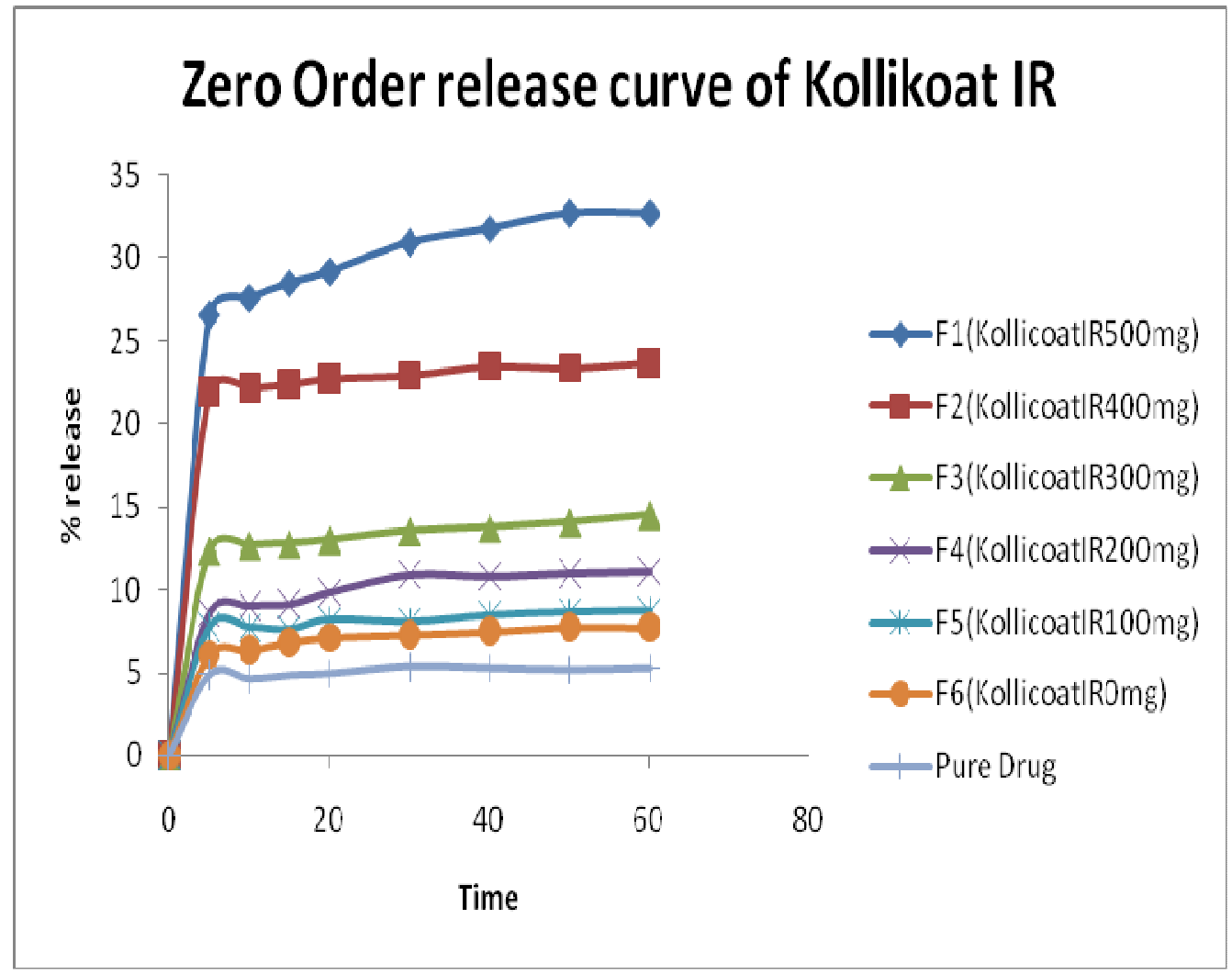

FIG. 1. Drug release from Kollicoat IR formulations

\section{Comparison of \% release of Drug from Formulation of Kollidon VA 64}

From the curve (Fig. 2) it is observed that increasing of Kollidon VA 64 when other polymer were fixed, the drug release was increased significantly. In the case of pure drug, release was decreased than drug with the combination of other polymer. When Kollidon VA 64 was increased drug release from solid dispersion was increased significantly due to wetting ability and convert crystalline to amorphous. The formulation containing increased Kollidon VA 64 increased drug release. Similar studies were conducted, formulations of Biphenyl dimethyl dicarboxylate in Kollidon VA 64 solid dispersions remarkably improved the dissolution rate of the drug ${ }^{25}$. 


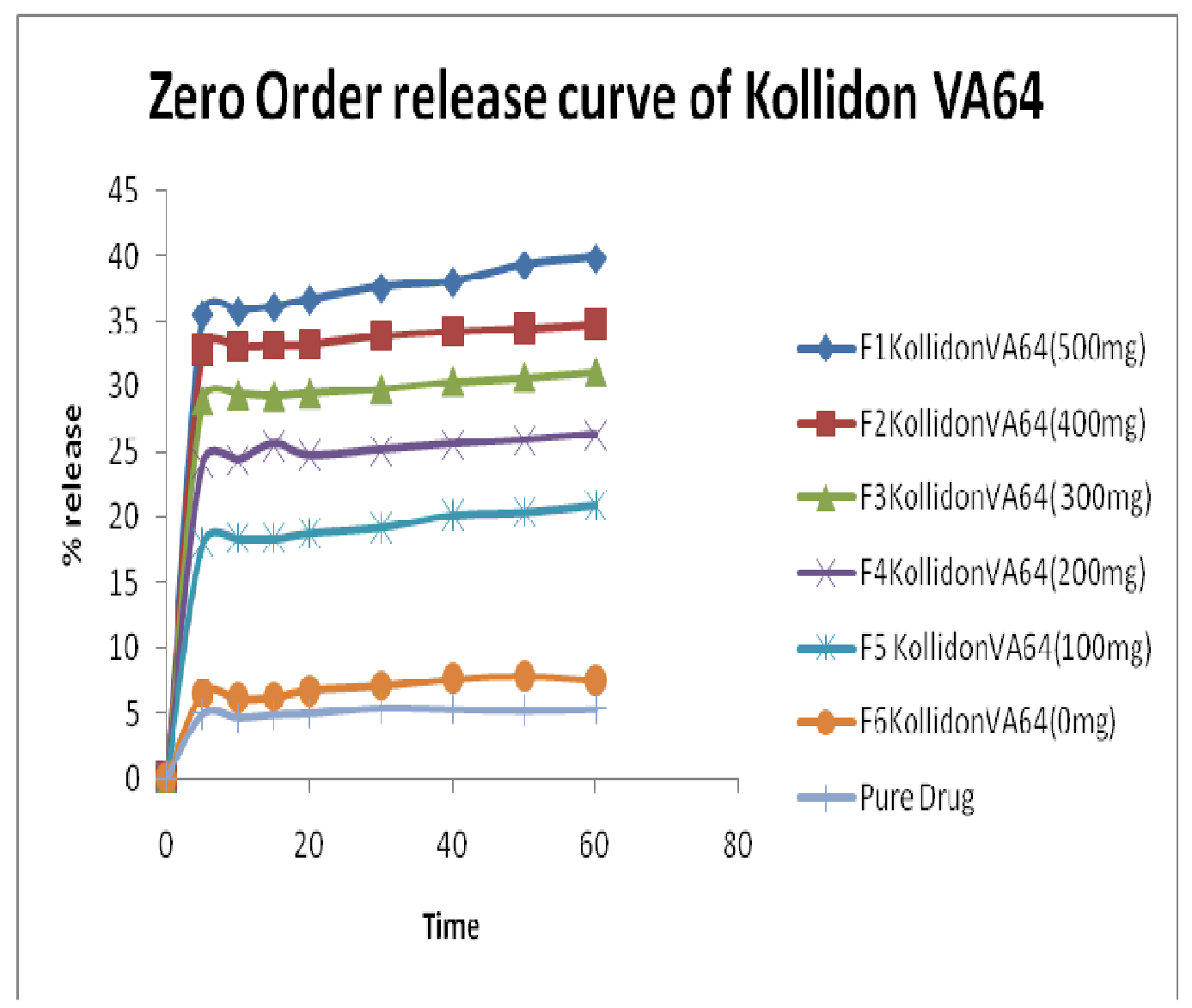

FIG. 2. Frug release from kollidon formulations

\section{Comparison of \% release of Drug from Formulation of Poloxomer407}

From the curve (Fig. 3) it is observed that increasing of Poloxomer when other polymer were fixed, the drug release was increased significantly. In the case of pure drug, release was decreased than drug with the combination of other polymer. When poloxomer is increased drug release from solid dispersion was increased significantly due to wetting ability and convert amorphous to crystalline. The formulation containing increased poloxomer increased drug release. Poloxamer 407 can act as gelling agent at high concentration and it can affect drug dissolution from solid dispersions. Drug release was very rapid compared to other polymers ratios. 
International Journal of Pharmaceutical and Life Sciences

ISSN 2305-0330

Volume 1, Issue 2, Serial 2: September 2012

But similar to HPMC, higher amount of poloxamer facilitated drug release. When the poloxomer concentration was decreased the drug release was also decreased.

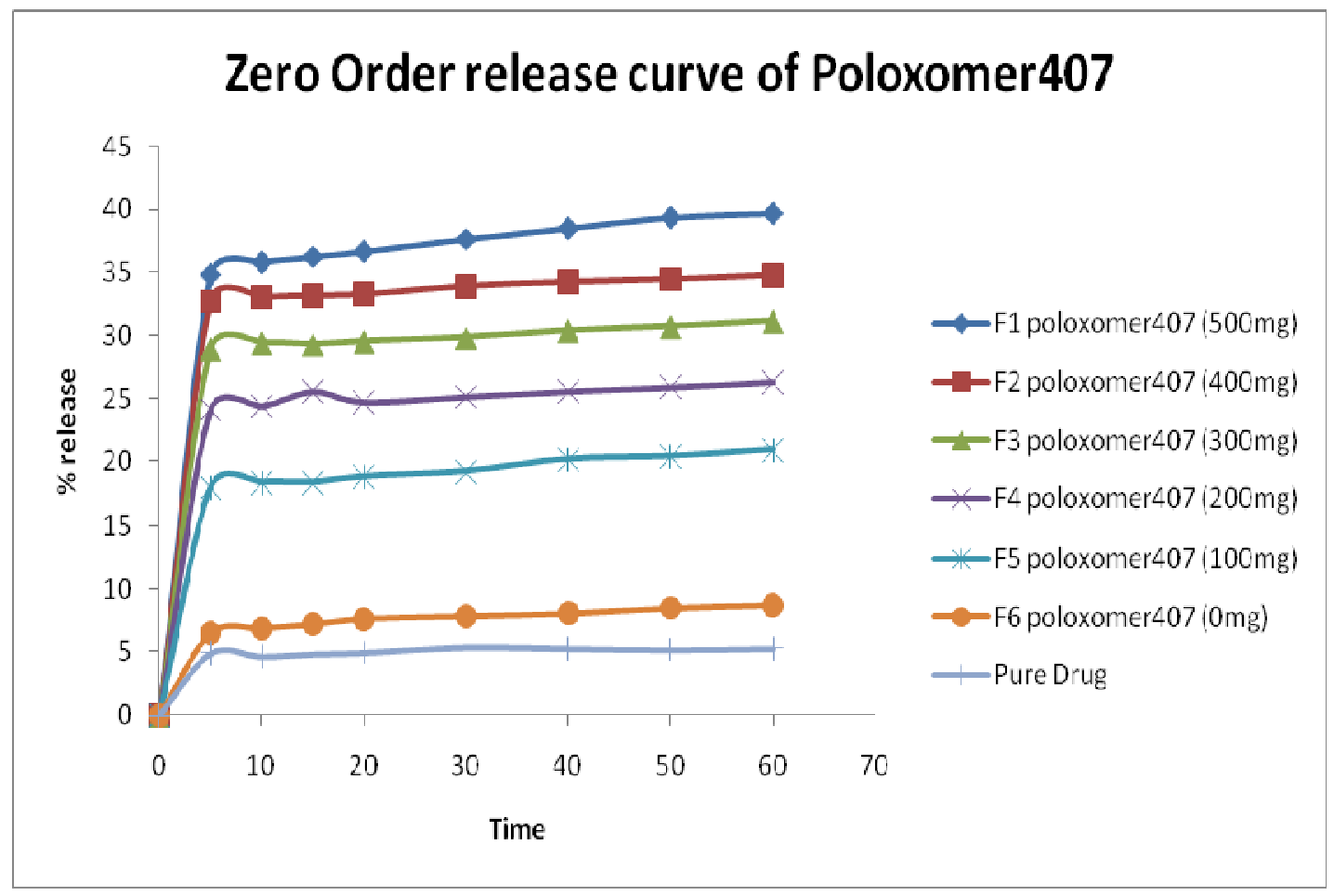

FIG. 3. Drug release from ploxomer formulations

Although dissolution rate for poorly water-soluble drug can be enhanced by converting the drug into its amorphous form ${ }^{26}$ but it can be thermodynamically unstable, and under certain levels of heat and humidity, could recrystallize into a more stable, poorly water-soluble form ${ }^{27}$. Clonazepam could be crystallized out of the formulations from poloxamer containing solid dispersions after contact with aqueous media. Poloxomers rapidly dissolved away from the solid dispersions and amorphous clonazepam reverted back to its crystalline state.

It was reported that molecular dispersion is one of the important roles of drug release from the polymer-drug system. The present work shows that the dissolution rate of 
Volume 1, Issue 2, Serial 2: September 2012

Clonazepam from solid dispersions with PEG 6000 and poloxomer was improved compared to the pure drug. Further, solid dispersions performed better than the corresponding physical mixtures. Various studies have shown that freely water soluble carriers inhibit crystallization of drugs in solid dispersions resulting in amorphous form of the drug in the solid dispersions ${ }^{28,29}$. Crystallization inhibition is attributed to two effects: interactions, such as hydrogen bonding between the drug and the polymer and the entrapment of the drug molecules in the polymer matrix during solvent evaporation or a combination of both. The present study confirmed the advantage of improved aqueous solubility of Clonazepam in its solid dispersions form, which can be formulated as tablets with better dissolution characteristics.

\section{Conclusion}

Solid dispersions prepared from polymers using the solvent evaporation method were effective in improving drug dissolution. Solid dispersion is proven to be a useful technique to improve the solubility of poorly soluble drugs like Clonazepam. All cases increasing polymeric content in the solid dispersions, increased drug release from prepared solid dispersions. The dispersion containing Poloxomer and Kollidon VA 64 showed acceptable dissolution compared to the Kollicoat IR dispersion or pure drug. The study revealed that optimum levels of hydrophilic carriers and hydrophillic porous adsorbants ensure a prompt and complete dissolution of clonazepam from solid dispersions that can be used in oral pharmaceutical formulations. For the development of solid dispersions depending on experimental data, it is concluded that the type of polymer and drug-polymer ratio are the critical factors. 
Volume 1, Issue 2, Serial 2: September 2012

\section{Acknowledgement}

The authors are thankful to Bangladesh University, University of Asia pacific and the University of Dhaka for their supports and co-operations.

\section{References}

1. Yamashita, K.; Nakate, T.; Okimoto, K.; Ohike, A.;et al Establishment of new preparation method for solid dispersion formulation of tacrolimus. Int. J. Pharm. 2003, 267, 79-91.

2. Leuner C, Dressman J. Improving drug solubility for oral delivery using solid dispersions. Eur J Pharm Biopharm 2000; 50:47-60.

3. Chiou WL, Rigelman S. Pharmaceutical application of solid dispersion system. J Pharm Sci 1971; 60:1281-1302.

4. Yh-Nam, P.; Jing-Huey C.; Russel, R.C.et al Enhancement of dissolution and bioavailability of piroxicam in solid dispersions systems, Drug Dev. Ind. Pharm. 2000, 26, 989-994.

5. Van den Mooter, G.; Augustijns, P.; Blaton, et al ..Physicochemical characterization of solid dispersions of temazepam with polyethylene glycol 6000 and PVP K30. Int. J. Pharm. 1998, 164, 67-80.

6. M. C. Gohel and L. D. Patel, Improvement of nimesulide dissolution from solid dispersions containing crosscarmellose sodium and Aerosilß 200, Acta Pharm. 52 (2002) 227-241.

7. United States Pharmacopoeia, 23, NF 18, The USP Convention, Rockville 1995, pp. 1791-1799. 


\section{International Journal of Pharmaceutical and Life Sciences \\ ISSN 2305-0330}

Volume 1, Issue 2, Serial 2: September 2012

8. Costantino HR, Firouzabadian L, Wu C, Carrasquillo KG, Griebenow K, Zale SE and Tracy MA (2002). Protein spray freeze drying. 2. Effect of formulation variables on particle size and stability. J. Pharm. Sci., 91(2): 388-395.

9. Skerritt JH, Johnston GA. Enhancement of GABA binding by benzodiazepines and related anxiolytics. Eur J Pharmacol. 1983;89(34):193-198.

10. Lehoullier PF, Ticku MK. Benzodiazepine and beta-carboline modulation of GABA-stimulated $36 \mathrm{Cl}$-influx in cultured spinal cord neurons. Eur $\mathrm{J}$ Pharmacol. 1987;135(2):235-238.

11. Proudfoot S. Factors affecting bioavailability: factors influencing drug absorption from the gastrointestinal tract. In: Aulton ME, editor. Pharmaceutics: the science of dosage from design. Edinburgh: Churchill Livingstone; 1991. pp. 135-173.

12. Douroumis D, Bouropoulos N, Fahr A. Physicochemical characterization of solid dispersions of three antiepileptic drugs prepared by solvent evaporation method. J Pharm Pharmacol 2007; 59: 645-653.

13. Nair R, Gonen S, Hoag SW. Influence of polyethylene glycol and povidone on the polymorphic transformation and solubility of carbamazepine. Int $\mathrm{J}$ Pharm 2002; 240: 11-22.

14. Rane Y, Mashru R, Sankalia M, Sankalia J. Effect of Hydrophilic Swellable Polymers on Dissolution Enhancement of Carbamazepine Solid Dispersions Studied Using Response Surface Methodology. AAPS PharmSciTech 2007; 8 (2):Article 27. 
15. Chen Y, Zhang GGZ, Neilly J, Marsh K, Mawhinney D, Sanzgiri YD. Enhancing the bioavailability of ABT-963 using solid dispersion containing pluronic F-68. Int J Pharm 2004; 286:69-80.

16. Passerini N, Gonzalez-Rodriguez ML, Cavallari C, Rodriguez L, Albertini B. Preparation and characterization of ibuprofen-poloxamer 188 granules obtained by melt granulation. Eur J Pharm Sci 2002; 15:71-78.

17. Yu H, Chun MK, Choi HK. Preparation and characterization of piroxicam/poloxamer solid dispersion prepared by melting method and solvent method. J Kor Pharm Sci 2007; 37:1-5.

18. Newa M, Bhandari KH, Oh DH, Kim YR, Sung JH, Kim JO, Woo JS, Choi HG, Yong CS. Enhanced Dissolution of Ibuprofen Using Solid Dispersion with Poloxamer 407. Arch Pharm Res 2008; 31(11):1497-1507.

19. Shah TJ, Amin AF, Parikh JR, Parikh RH. Process Optimization and Characterization of Poloxamer Solid Dispersions of a Poorly Water-soluble Drug. AAPS PharmSciTech 2007; 8 (2): Article 29.

20. Chokshi RJ, Zia H, Sandhu HK, Shah NH, Malick WA. Improving the Dissolution Rate of Poorly Water Soluble Drug by Solid Dispersion and Solid Solution-Pros and Cons. Drug Delivery 2007; 14:33-45.

21. Ibrahim S Khattab, Aly Nada, Abdel-Azim Zaghloul. Physicochemical characteristics of gliclazide-macrogel solid dispersions and tablets based on optimized dispersion. Drug Dev Ind Pharma. 2010, 36 (8): 893-902

22. Yadav VB, Yadav AV. Enhancement of solubility and dissolution rate of indomethacin with different polymers by compaction process. Chem Tech.2009, 01, 4: 1072-1078. 
Volume 1, Issue 2, Serial 2: September 2012

23. Janssen S, Armas HN, Remon JP, Mooter GV. The use of a new hydrophilic polymer, Kollicoat IR $\AA^{\circledR}$, in the formulation of solid dispersions of itraconazole. Eur J Pharm Sci 2007;30:288-294.

24. Ribeiro L, Ferreiro DC, Veiga FJB. In vitro controlled release of vinpocetinecyclodextrin-tartaric acid multicomponent complexes from HPMC swellable tablets. J Control Release 2005; 103: 325-339.

25. Jee-Hyun Moon, In Koo chun. Dissolution characteristics of Biphenyl dimethyl dicarboxylate from solid dispersions with copolyvidone. Korea society of applied pharmacology. 1997, pp. 118-119.

26. Hancock BC, Parks M. What is the true solubility advantage for amorphous pharmaceuticals? Pharm Res 2000; 17:397-404.

27. Matsuda Y, Kawaguchi S. Physicochemical characterization of oxyphenbutazone and solid-state stability of its amorphous form under various temperature and humidity conditions. Chem Pharm Bull 1986; 34:1289-1298.

28. Van DMG, Augustijns P, Blaton N, Kinget R. Physicochemical characterization of solid dispersions of temazepam with polyethylene glycol 6000 and PVP K30. Int J Pharm 1998;164:67-80.

29. KPR, Murthy KVR, Hayman AR, Becket G. Physicochemical characterization of nimesulide- cyclodextrin binary systems. AAPS PharmSciTech 2003, 4 (1) article 7:1-12. 